\title{
The role of omega-3 fatty acids in child development ${ }^{*}$
}

\author{
Saskia JM OSENDARP \\ Unilever $R \& D$ Vlaardingen, \\ The Netherlands \& Division of Human \\ Nutrition, \\ Wageningen University, \\ The Netherlands \\ <saskia.osendarp@unilever.com>
}

\begin{abstract}
Omega-3 long chain polyunsaturated fatty acids ( $n$-3 LCPUFA) are important constituents of the maturing brain and therefore considered crucial for brain development in utero and in early infancy. However, it is uncertain whether $n-3$ LCPUFA supplementation during pregnancy and lactation can have beneficial, sustainable effects on visual or cognitive development. Beneficial effects on child cognitive function after supplementation with EPA and DHA during pregnancy and lactation were observed at 4 years of age, but not at 3, 6 months or 7 years. In term infants LCPUFA when given in relative high dosages, seems to improve visual acuity, but not cognitive function. Evidence for an effect of LCPUFA supplementation of preterm infants remains inconclusive. In children older than 2 years of age, epidemiological evidence suggests an association between psychiatric or neurodevelopmental disorders and omega-3 fatty acid deficiencies. However, the evidence from randomized controlled trials exploring the impact of omega-3 fatty acids on cognitive performance or brain function in school-aged children is not conclusive. In conclusion, $n-3$ LCPUFA are highly present in the maturing brain and are important for normal brain functioning and development. When provided in relative high dosages, $n$ - 3 LCPUFA may improve visual acuity in term infants. However, it remains unclear whether supplementation with $n-3$ LCPUFA during pregnancy, early infancy, and childhood can improve cognitive function.
\end{abstract}

Key words: child development, omega-3 fatty acids, neurodevelopmental disorders psychiatric disorders

brane fluidity, membrane activity-bound enzymes, number and affinity of receptors, function of neuronal membrane ionic channels, and production of neurotransmitters and brain peptides (Yehuda, 2003). Although DHA and AA are the major structural components of the central nervous system, there is currently no consensus whether dietary supplementation of LCPUFA has benefits for visual and cognitive development of infants.

\section{Evidence from pregnant and lactating mothers}

There is suggestive evidence for a beneficial effect of early exposure to n-3 fatty acids on children's cognitive development. Repeatedly, positive findings on a beneficial effect of $n-3$ fatty acid supplementation or fish intake during pregnancy and/or lactation on developmental outcomes of the offspring (> 2 years) were reported from both observational studies and randomized controlled trials (RCTs) (figure 1).

Three RCTs from high-income countries supplemented with $\mathrm{n}-3$ fatty acids during pregnancy. Two of these trials reported improvements in problem solving at 9 months of age (Judge et al., 2007) or hand-eye coordination at 30 months of age (Dunstan et al., 2008). However, as a lot of outcome measures were tested in these RCTs without adjusting p-values accordingly, positive findings may have been due to chance. In contrast, one recent large study with high-DHA fishoil in Australia did not observe benefits in cognitive and language scores at 18 months of age after maternal supplementation during pregnancy (Makrides et al., 2010).

Two intervention trials on prenatal supplementation with n-3 LCPUFA have
Brain II" held by The French Society for the Study of Lipids (Sfel) - Paris 28-30 March 2011, cf. OCL 18-4 and 18-5.

To cite this article: Osendarp SJM. The role of omega-3 fatty acids in child development. OCL $2011 ; 18(6)$ : 307-313. doi : 10.1684/ ocl.2011.0417 


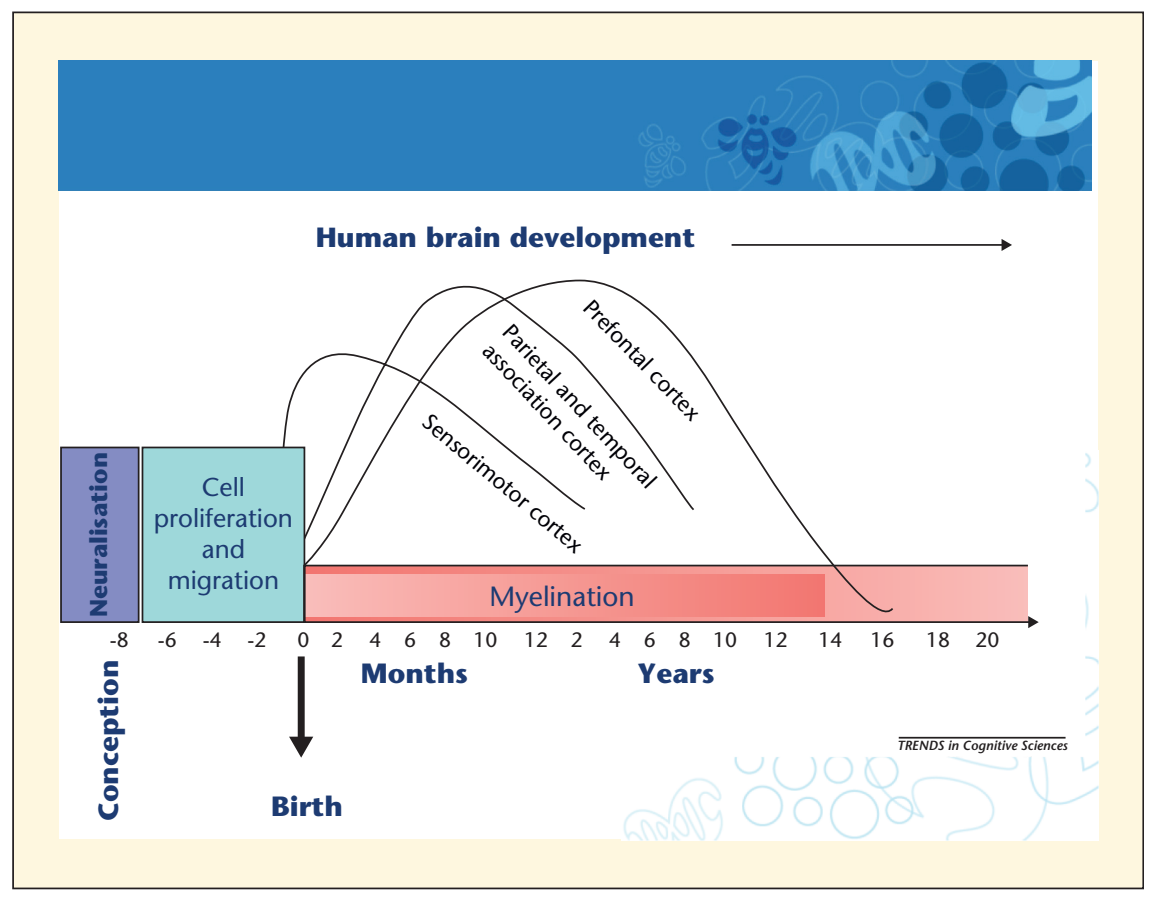

Figure 1. Brain development in childhood. Adapted from Thompson, RA, Nelson CA. Development. Am Psychol 2001; 56: 5-15. Animation: Gogtay et al., 2007

been conducted in low-income countries: in Bangladesh and Mexico. Both studies did not observe differences between infants from treated and control mothers in development scores at 10 or 18 months of age were observed (Tofail et al., 2006; Ramakrishan et al., 2010).

One study reported on the effects of maternal supplementation with $803 \mathrm{mg}$ EPA and $1183 \mathrm{mg}$ DHA from 18 weeks gestation until 3 months postpartum. Beneficial effects were observed on mental processing index at 4 years (Helland et al., 2003; Helland et al., 2008) but not any more at 7 years of age. Infant, maternal or cord blood DHA status was repeatedly found to be positively correlated to cognitive outcomes (Helland 2003 et al.;; Helland et al., 2008; Dunstan et al., 2008).

Overall, there is no consistency with regard to the areas of mental development that might benefit from maternal n-3 fatty acid supplementation; improvements were reported for general IQ, memory, verbal, motor performance, attention, hyperactivity and social behaviour.

A recent Cochrane review (DelgadoNoguera et al., 2010) on the effects of supplementation with LCPUFA to breast- intake during pregnancy and/or lactation on developmental outcomes of the offspring up to 14 years were reported from observational studies. The small number of RCTs, however, reported only few positive findings on single outcome measures, which may have been due to chance. Overall, there is no consistency in the benefits observed, with improvements being reported for general IQ, memory, verbal, motor performance, attention, hyperactivity and social behaviour.

\section{Evidence from term and pre-term infants}

Evidence on the effects of LCPUFA during infancy have been well-documented and summarised in recent meta-analysis. Overall, there is no good evidence for a beneficial effect of LCPUFA supplementation on mental development in infants $(<2$ yr). A recent meta-analysis on the effects of LCPUFA supplementation of pre-term infants on neurodevelopment up to 18 months of age reported that four out of seven studies did not show a benefit; the three trials which showed improvements on cognitive development scores all used the newer version of the Bayles Scales of Infant Development, suggesting that the effects may have been too subtle to be detected with other methods (Schulzke et al., 2011). No beneficial effects of LCPUFA supplementation on visual development were seen either (Schulzke et al., 2011). A meta-analysis on the effects of LCPUFA supplementation in term infants did not show an effect on either mental or psychomotor development (Simmer et al., 2008). Outcomes on visual acuity were inconsistent, with six out of nine studies not showing a beneficial effect. Beneficial effects on visual acuity in term infants were seen with higher doses of DHA $(0.35 \%$ or $0.36 \%$ in formula) and when measured by electrophysiological tests.

\section{Evidence from healthy children}

Studies in healthy children ( $>2 \mathrm{yr}$ ) do not show consistent beneficial effects of a DHA or EPA supplementation. In total, seven out of ten randomised controlled intervention studies in 4-14 year old children did not find a beneficial effect 
LCPUFA on cognitive outcomes (Kirby et al., 2010; Kennedy et al., 2009; Muthayya et al., 2009; Ryan et al., 2008; Osendarp et al., 2007; de Jong et al., 2010). The dosages used in this trial varied significantly and ranged from 100 $1,200 \mathrm{mg}$ DHA/EPA per day. In addition, all of these RCTs had some quality limitations, like a low intervention dose, a too short intervention period, use of non-validated tests, tests in non-native language, ceiling effect, multiple assessors, inappropriate control product, a small sample size, which might explain the lack of positive findings.

Three RCTs did find some beneficial effects (Dalton et al., 2009; McNamara et al., 2010; Portwood, 2011). One RCT in South African children of low SES with a habitual low fish intake found significant effects of a spread fortified with fish flour on verbal recognition, discrimination and spelling (Dalton et al.,
2009). The positive effects found cannot for sure be contributed to EPA \& DHA as the fish flour also contains vitamins and minerals which might have had an effect. An fMRI study in 33 UK boys found significantly increased cortical activation during a sustained attention task upon eight weeks of supplementation with 400 or $1200 \mathrm{mg} / \mathrm{d}$ DHA (McNamara et al., 2010), but no differences between groups in behavioural test outcomes. Another study in UK children found significant effects of a three month intervention with EPA $(558 \mathrm{mg} / \mathrm{d})$, DHA $(174 \mathrm{mg} / \mathrm{d})$ and GLA $(60 \mathrm{mg} / \mathrm{d})$ on reading age and working memory but not on behaviour. However, this study had some quality limitations and is still not published in a peer-reviewed paper (Portwood, 2011).

Observational (cross-sectional and longitudinal) studies in healthy children suggest that there might be a positive relationship between n-3 FA or fish intake and cognitive outcomes.

Five cross-sectional studies assessing 4$16 \mathrm{yr}$ old children found a significant positive association between fish, n-3, or total PUFA intake and at least some cognitive outcomes (Kirby et al., 2010, Theodore et al., 2009; Kim et al., 2009; Zhang et al., 2005, Freire et al., 2010). Two other studies did not find any significant associations (Mendez et al., 2008, Eilander et al., 2010).

Five longitudinal studies, followed children form birth to childhood (Bakker et al., 2003, 2009; Ghys et al., 2002; Gale et al., 2010) or throughout childhood (Rask-Nissila et al., 2002; Aberg et al., 2009); two studies showed significant beneficial effects of DHA fortified formula during the first 6 months (Gale et al., 2010) and fish intake during adolescence (Aberg et al., 2009) on children's overall

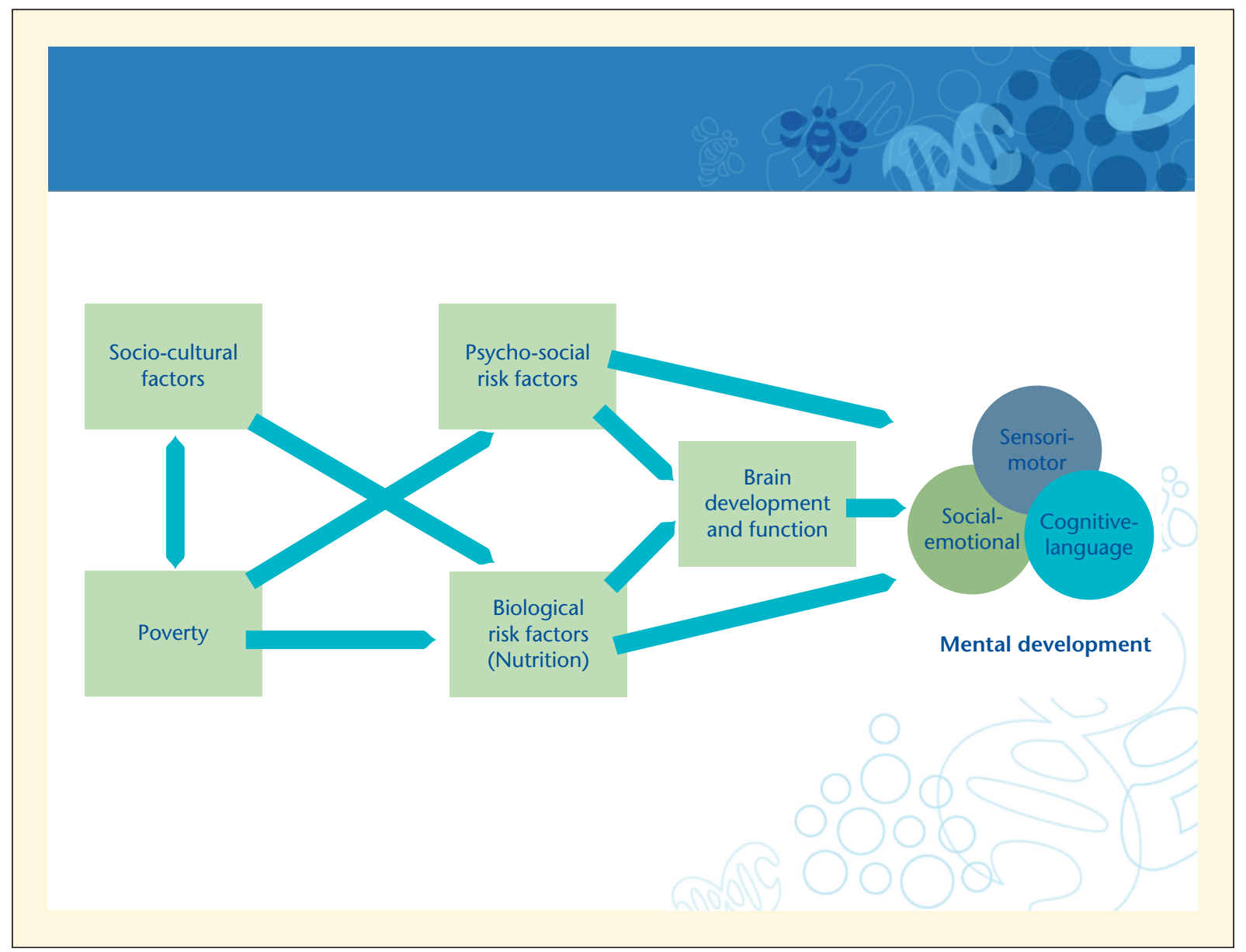

Figure 2. Conceptual framework on role of nutrition in mental development. Adapted from Walker et al., Lancet 2007 
cognitive outcome measures. Other studies did not show an association between DHA status at birth or intake during the first six months with cognitive performance at 4 or $7 \mathrm{yr}$ of age (Bakker et al., 2003; Ghys et al., 2002), but a positive relationship with improved motor performance at 5 (Rask-Nissila et al., 2002) and 7 years of age (Bakker et al., 2009) (figure 2).

In summary, there is suggestive evidence - from observational studies - of a positive relationship between $n-3$ FA status at birth or fish intake during childhood and developmental outcomes in healthy children up to the age of 18 years. Yet the results might be confounded by other influencing factors and don't prove a cause-effect relationship. The potential beneficial effects are not confirmed in intervention trials. The majority (i.e. 7 out of 10) of randomized controlled intervention trials in healthy children does not show an effect of n-3 fatty acid supplementation on cognitive outcomes.

\section{Evidence from diseased populations}

There is some evidence from studies in children with phenylkenonuria (PKU) on the role of $n-3$ fatty acids in neurotransmission and behavioural outcomes. Children with PKU have very low natural intakes of EPA and DHA due to dietary restrictions (but a good supply of ALA). Two studies (one of them an open label study) in treated PKU children showed that these children had prolonged visual evoked potentials compared to healthy controls. After supplementation with DHA, EPA (+ALA and AA) wave latency of visual evoked potentials decreased in both studies, indicating more rapid central nervous system information processing (Beblo et al., 2001). The open-label study also showed significant improvements of EPA+DHA supplementation on a test of motor function and coordination (Beblo et al., 2007). When the subjects of the controlled trial were assessed again three years later after the end of the treatment to see whether improvements had lasted in the longer term, initial improvements had returned to baseline (Agostini et al., 2003).

In addition, there is some evidence from EPA/DHA intervention studies on cognitive functioning in children with deve- lopmental disorders. Evidence from studies in children with ADHD show some positive findings on self-reported behaviour. Four (Richardson and Puri, 2002; Stevens et al., 2003; Sinn, 2007; Johnson et al., 2009) out of five (Raz et al., 2009) randomized controlled trials supplementing a mix of $n-3$ fatty acids (120$730 \mathrm{mg} / \mathrm{d}$ ) and n-6 fatty acids (60 to $135 \mathrm{mg} / \mathrm{d}$ ) showed improvements on self-reported ADHD symptoms. Six more studies of varying quality, two of them were open-label studies, supplemented n-3 fatty acids alone (Voigt et al., 2001; Hiramaya et al., 2004; Joshi et al., 2006; Sorgi et al., 2007; Vaisman et al., 2008; Gustafsson et al., 2010). Only the openlabel studies showed a significant effect of ALA (400 mg/d) or very high doses of EPA/DHA (16 g/d) on behavioural outcomes (Joshi et al., 2006; Sorgi et al., 2007). Three of the four randomized controlled trials supplementing DHA (+EPA) point into the same direction (Voigt et al., 2001; Vaisman et al., 2008; Gustafsson et al., 2010) (figure 2).

\section{Discussion and conclusion}

LCPUFA and DHA in particular are abundantly present in the human developing brain. However, the evidence base for a beneficial effect of dietary LCPUFA on child's development is thin and has inconsistent findings. Supportive evidence for a beneficial role of $n-3$ fatty acids in cognitive functioning is mainly coming from studies in specific patient groups (PKU) or children with developmental disorders (ADHD, neurophysiologic diseases, n-3 deficiency). It is questionable however, how far this evidence can be extrapolated to the general population.

It is unfortunate that most of the intervention studies reported to date suffer from methodological limitations. Failure to find positive effects of LCPUFA on child development might have been due to intervention dosages which were too low, too short interventions, limitations related to the use of psychological tests, inappropriate control products and small sample sizes. On the other hand, trials which did demonstrate positive effects, may in fact have reported falsepositive findings particularly due to a high number of test outcomes included and the possibility of chance findings.
The question whether additional dietary supply of DHA, is required for cognitive functioning after the age of 2 years, remains therefore unanswered.

Rapoport et al. (2007) studied the turnover of DHA in the human brain by measuring the daily incorporation of radio-labelled DHA into the brain. He stated that the incorporation rate of DHA equal the rate of loss because DHA cannot be synthesized de novo in the brain, neither does its precursor (ALA) contribute significantly $(<1 \%)$ to brain DHA. He found that the adult brain uses and replaces $4.6 \mathrm{mg}$ of DHA per day. This suggests that DHA in the brain might need to be replenished to maintain certain levels. However, in a rat study Rapoport et al. also showed that the rate of liver synthesis of DHA from ALA was more than sufficient to maintain brain DHA (Rapoport et al., 2007).

As several studies in specific patient groups (ADHD, PKU) showed that EPA/ DHA supplementation had a beneficial effect on functional cognitive outcomes (primarily behaviour related) one can hypothesise that dietary fatty acids do arrive at the target organ and that they are indeed used in their role in cognitive functioning. However, this would still need to be confirmed.

Because the conversion of ALA to DHA is very limited, many health authorities currently advice to ensure a minimum intake of DHA and EPA from the diet, despite the fact that in principle the body should be able to make these fatty acids. EPA and DHA are for that reason considered "conditionally essential" (Uauy and Dangour, 2009).

Recommendations for the intake of EPA and DHA for adults are mainly based on primary and secondary prevention of cardiovascular disease (CVD; 250$500 \mathrm{mg} / \mathrm{d}$ EPA+DHA or 1-2 portions of fatty fish per week). For children from 210 years the FAO recently set recommendations for an adequate EPA and DHA intake, i.e. 100 to 250 mg (depending on the age) (FAO, 2010) in line with adults aiming at the early prevention of chronic disease (Koletzko et al., 2010). In children and adults, PUFA intakes are generally below the recommendations. Also EPA and DHA intakes are lower than recommended; however, data are very limited (Harika et al., 2011). Despite the on-going debate on the exact role of LCPUFA in cognitive, efforts to increase 


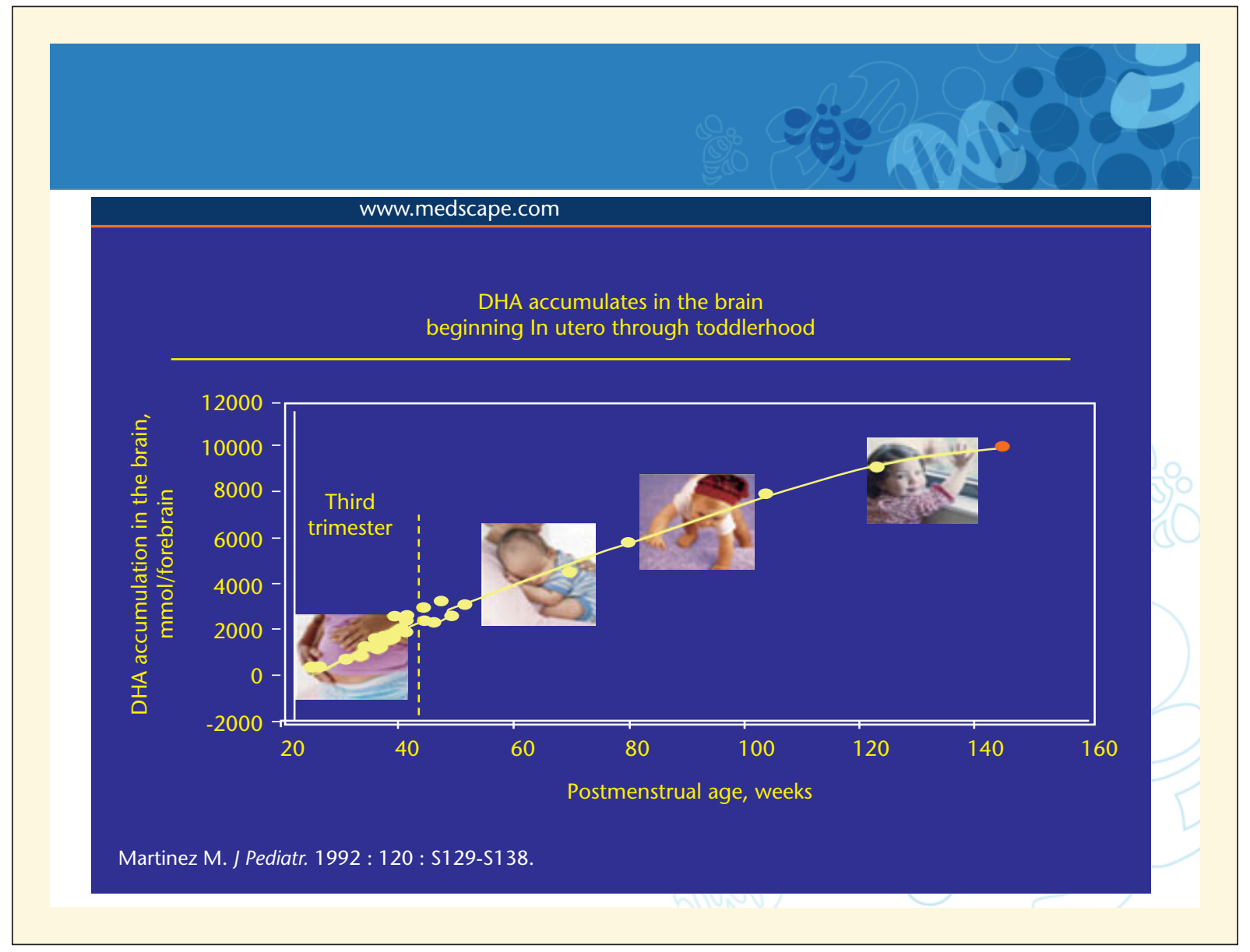

Figure 3. Brain DHA during gestation and early childhood. Adapted from Martinez M. J Pediatr 1992, 120: S129-s138

consumption of these fatty acids in children should therefore be supported (figure 3).

\section{REFERENCES}

Aberg, et al. Fish intake of Swedish male adolescents is a predictor of cognitive performance. Acta Paediatr 2009; 98: 555-60.

Agostini C, Verduci E, Massetto N, et al. Long term effects of long chain polyunsaturated fats in hyperphenylalaninemic children. Arch Dis Child 2003; 88: 582-3.

Bakker, et al. Long-chain polyunsaturated fatty acids at birth and cognitive function at 7 y of age. Eur J Clin Nutr 2003; 57: 89-95.

Bakker, et al. Relationship between longchain polyunsaturated fatty acids at birth and motor function at 7 years of age. Eur J Clin Nutr 2009; 63: 499-504.

Beblo S, Reinhardt H, Muntau AC, MuellerFelber W, Roscher AA, Koletzko B. Fish oil supplementation improves visual evoked potentials in children with phenylketonuria. Neurology 2001; 57: 1488-91.

Beblo S, Reinhardt H, Demmelmair H, Muntau AC, Koletzko B. Effect of fish oil supplementation on fatty acid status, coordination, and fine motor skills in children with phenylketonuria. J Pediatr 2007; 150: 479-84.

Budtz-Jorgensen, et al. Separation of Risks and Benefits of Seafood Intake. Environ Health Perspect 2007; 115: 323-7.

Clandinin MT, Chappell JE, Leong S, Heim T, Swyer PR, Chance GW. Extrauterine fatty acid accretion in infant brain: implications for fatty acid requirements. Early Hum Dev 1980; 4: 131-8.

Dalton, et al. A randomised control trial in schoolchildren showed improvement in cognitive function after consuming a bread spread, containing fish flour from a marine source. Prostaglandins Leukot Essent Fatty Acids 2009; 80 :143-9.
Delgado-Noguera MF, Calvache JA, Bonfill Cosp X. Supplementation with long chain polyunsaturated fatty acids (LCPUFA) to breastfeeding mothers for improving child growth and development. Cochrane Database Syst Rev 2010; (12): CD007901.

de Jong, et al. The Groningen LCPUFA study: no effect of postnatal long-chain polyunsaturated fatty acids in healthy term infants on neurological condition at 9 years. Br J Nutr 2010; 104: 566-72.

Dobbing J, Sands J. Quantitative growth and development of human brain. Arch Dis Child 1973; 48: 757-67.

Dunstan, et al. Cognitive assessment of children at age $2(1 / 2)$ years after maternal fish oil supplementation in pregnancy: a randomised controlled trial. Arch Dis Child Fetal Neonatal Ed 2008; 93: F45-50.

Eilander, et al. Undernutrition, fatty acid and micronutrient status in relation to cognitive performance in Indian school children: a 
cross-sectional study. Br / Nutr 2010; 103: 1056-64.

FAO. Fats and fatty acids in human nutrition. Report of an expert consultation. Food and Nutrition paper 91. Rome 2010.

Freire C, Ramos R, Lopez-Espinosa MJ, et al. Hair mercury levels, fish consumption, and cognitive development in preschool children from Granada, Spain. Environ Res 2010; 110: 96-104.

Gale, et al. Oily fish intake during pregnancy - association with lower hyperactivity but not with higher full-scale IQ in offspring. / Child Psychol Psychiatry 2008; 49: 1061-8.

Gale, et al. Breastfeeding, the use of docosahexaenoic acid-fortified formulas in infancy and neuropsychological function in childhood. Arch Dis Child 2010; 95: 174-9.

Ghys et al., Red blood cell and plasma phospholipid arachidonic and docosahexaenoic acid levels at birth and cognitive development at 4 years of age. Early Hum Dev 2002; 69: 83-90.

Gustafsson PA, Birberg-Thornberg U, Duchén $\mathrm{K}$, et al. EPA supplementation improves teacher-rated behaviour and oppositional symptoms in children with ADHD. Acta Paediatr 2010; 99: 1540-9.

Helland, et al. Maternal supplementation with very-long-chain n-3 fatty acids during pregnancy and lactation augments children's IQ at 4 years of age. Pediatrics 2003; 111: e39-44.

Helland, et al. Effect of supplementing pregnant and lactating mothers with n-3 very-long-chain fatty acids on children's IQ and body mass index at 7 years of age. Pediatrics 2008; 122: e472-9.

Hibbeln, et al. Maternal seafood consumption in pregnancy and neurodevelopmental outcomes in childhood (ALSPAC study): an observational cohort study. Lancet 2007; 369: 578-85.

Hiramaya S, Hamazaki T, Terasawa K. Effect of docosahexaenoic acid-containing food administration on symptoms of attentiondeficit/hyperactivity disorder - a placebocontrolled double-blind study. Eur / Clin Nutr 2004; 58: 467-73.

Jensen, et al. Effects of early maternal docosahexaenoic acid intake on neuropsychological status and visual acuity at five years of age of breast-fed term infants. I Pediatr 2010; 157: 900-5.

Johnson M, Ostlund s, Fransson G, Kadesjö B, Gillberg C. Omega-3/omega-6 fatty acids for attention deficit hyperactivity disorder: a randomized placebo-controlled trial in children and adolescents. J Atten Disord 2009; 12: 394-401.

Joshi K, Lad S, Kale M, et al. Supplementation with flax oil and vitamin $C$ improves the outcome of Attention deficit Hyperactivity Disorder (ADHD). Prostaglandins Leukot Essent Fatty Acids 2006; 74: 17-21.

Judge MP, Harel O, Lammi-Keefe CJ. Maternal consumption of a docosahexanoic acidcontaining functional food during pregnancy: benefit for infant performance on problem-solving but not on recognition memory tasks at 9 mo of age. Am J Clin Nutr 2007; 85: 1572-7.

Harika RK, Cosgrove MC, Osendarp SJM, Verhoef P, Zock PL. Fatty acid intakes of children and adolescents around the world are lower than recommended for future cardiovascular health: a review of dietary intake data. B J Nutr 2011(in press); doi: $10.1017 /$ S0007114511001528.

Kennedy et al. Cognitive and mood effects of 8 weeks' supplementation with $400 \mathrm{mg}$ or $1000 \mathrm{mg}$ of the omega- 3 essential fatty acid docosahexaenoic acid (DHA) in healthy children aged 10-12 years. Nutr Neurosci 2009; 12:48-56.

Kim J, Winkvist A, Aberg MAl, et al. Fish consumption and school grades in Swedish Adolescents: a study of the large general population. Acta Paediatrica 2010; 99: 72-7.

Kirby, et al. A double-blind, placebo-controlled study investigating the effects of omega-3 supplementation in children aged 8-10 years from a mainstream school population. Res Dev Disabil 2010a; 31: 718-30.

Kirby, et al. Childrens' learning behaviour and the association with cheek cell polyunsaturated fatty acid levels. Res Dev Disabil 2010b; 31: 731-42.

Koletzko B, Uauy R, Palou A, et al. Dietary intake of eicosapentaenoic acid (EPA) and docosahexaenoic acid (DHA) in children - a workshop report. Br J Nutr 2010; 103: 923-8.

Lederman et al., Relation between Cord Blood Mercury Levels and Early Child Development in a World Trade Center Cohort. Environ Health Perspect 2008; 116: 1085-91.

Makrides M, Collins CT, Gibson RA. Impact of fatty acid status on growth and neurobehavioral development in humans. Maternal Child Nutr 2011; 7 (Suppl .2): 80-8.

Martinez M, Tissue levels of polyunsaturated fatty acids during early human development. J Pediatr 1992; 120: S129-38.

McNamara, et al. Docosahexaenoic acid supplementation increases prefrontal cortex activation during sustained attention in healthy boys: a placebo-controlled, dose-ranging, functional magnetic resonance imaging study. Am / Clin Nutr 2010; 91: 1060-7.

Mendez et al., Maternal fish and other seafood intakes during pregnancy and child neurodevelopment at age 4 years. Public Health Nutr 2008 : 1-9.
Muthayya et al., Effect of fortification with multiple micronutrients and n-3 fatty acids on growth and cognitive performance in Indian schoolchildren: the CHAMPION (Children's Health and Mental Performance Influenced by Optimal Nutrition) Study. Am J Clin Nutr 2009; 89: 1766-75.

Oken et al., Maternal Fish Intake during Pregnancy, Blood Mercury Levels, and Child Cognition at Age 3 Years in a US Cohort. Am J Epidemiol 2008; 167: 1171-81.

Osendarp SJ, Baqhurst K, Bryan J, et al.; The NEMO study group. Effect of a 12-mo micronutrient intervention on learning and memory in well-nourished and marginally nourished school-aged children: 2 parallel, randomized, placebo-controlled studies in Australia and Indonesia. Am J Clin Nutr 2007; 86: 1082-93.

Portwood N. The Durham trial. http://www. durhamtrial.org/primary\%20main.htm. (accessed at 18 November 2011).

Ramakrishan U, Stein AD, Parra-Cabrera S, et al. Effects of docosahexanoic acid supplementation during pregnancy on gestational age and size at birth: randomized, doubleblind, placebo-controlled trial in Mexico. Food Nutrition Bulletin 2010l 31: S108-16.

Rapoport SI, Rao JS, Igarashi M. Brain metabolism of nutritionally essential polyunsaturated fatty acids depends on both the diet and the liver. Prostaglandins Leukot Essent Fatty Acids 2007; 77: 251-61.

Rask-Nissila L, Jokinen E, Terho P, et al. Effects of diet on the neurologic development of children at 5 years of age: the STRIP project. $)$ Pediatr 2002; 140: 328-33.

Raz R, Carasso RL, Yehuda S. The influence of short-chain essential fatty acids on children with attention-deficit/hyperactivity disorder: a double-blind placebo-controlled study. J Child Adolesc Psychopharmacol 2009; 19: 167-77.

Richardson AJ, Puri BK. A randomized doubleblind, placebo-controlled study of the effects of supplementation with highly unsaturated fatty acids on ADHD-related symptoms in children with specific learning difficulties. Prog Neuropsychopharmacol Bio Psychiatry 2002; 26: 233-9.

Ryan et al., Assessing the effect of docosahexaenoic acid on cognitive functions in healthy, preschool children: a randomized, placebo-controlled, double-blind study. Clin Pediatr (Phila) 2008; 47: 355-62.

Schulzke SM, Patole SK, Simmer K. Longchain polyunsaturated fatty acid supplementation in preterm infants. Cochrane Database of Systematic Reviews 2011, Issue 2.

Simmer K, Patole S, Rao SC. Longchain polyunsaturated fatty acid supplementation in infants born at term. Cochrane Database of Systematic Reviews 2008, Issue 1. 
Sinn N. Physical fatty acid deficiency signs in children with ADHD symptoms. Prostaglandins Leukot Essent Fatty Acids 2007; 77: 109-15.

Sorgi PJ, Hallowell EM, Hutchins HL, Sears B. Effects of an open-label pilot study with highdose EPA/DHA concentrates on plasma phospholipids and behaviour in children with attention deficit hyperactivity disorder. Nutr J 2007; 6: 16.

Stevens L, Zhan W, Peck L, et al. EFA supplementation in children with inattention, hyperactivity, and other disruptive behaviors. Lipids 2003; 38: 1007-21.

Strain JJ, Davidson PW, Bonham MP, et al. Associations of maternal long-chain polyunsaturated fatty acids, methyl mercury, and infant development in the Seychelles Child
Development Nutrition Study. Neurotoxicology 2008; 29: 776-82.

Theodore, et al. Dietary patterns and intelligence in early and middle childhood. Intelligence, 2009; 37: 506-13.

Tofail F, Kabir I, Hamadani JD, et al. Supplementation of fish-oil and soy-oil during pregnancy and psychomotor development of infants. I of Health, Population and Nutrition 2006; 24: 48-56.

Uauy R, Dangour AD. Dietary fat quality for optimal health and well-being: overview of recommendations. Ann Nutr Metab 2009; 54 (Suppl. 1): 2-7.

Vaisman N, Kaysar N, Zaruk-Adasha Y, et al. Correlation between changes in blood fatty acid composition and visual sustained atten- tion performance in children with inattention: effect of dietary n-3 fatty acids containing phospholipids. Am J Clin Nutr 2008; 87: 1170-80.

Voigt RG., Llorente AM, Jensen CL, Fraley JK, Berretta MC, Heird WC. A randomized, double-blind, placebo-controlled trial of docosahexaenoic acid supplementation in children with attention-deficit/hyperactivity disorder. J Pediatr 2001; 139: 189-96.

Yehuda S, Omega-6/omega-3 ratio and brain-related functions. World Rev Nutr Diet 2003; 92: 37-56.

Zhang, et al. Dietary fat intake is associated with psychosocial and cognitive functioning of school-aged children in the United States. J Nutr 2005; 135: 1967-73. 